\title{
Leech Infestation in the Vulvar Region: Causes of Vaginal Bleeding in a Six years old Child
}

\author{
Theodomir Sebazungua ${ }^{a}$ Pascaline Kioła Kabungo ${ }^{b}$, Emmanuel Manirakizac, Blaise \\ Dushimiyimana $^{d}$ \\ University of Rwanda, College of Medicine and Health Sciences, 'babaya District Hospital, 'Gisenyi District Hospital, dRuhengeri referral hospital \\ Correspondence to: Theodomir Sebazungu (t..sebazungu@yahoo.com)
}

\begin{abstract}
Background: Leeches are hermaphroditic rare blood-sucking human endoparasitesof phylum Annelida and class Hirudinea. Leech infestation is a zoonotic disease acquired by drinking contaminated water, swimming in ponds and streams. 'Epidemiology of leech bites in literature is limited and the majority of existing data are case reports from the tropics or subtropics. ${ }^{2-4}$

Leech bites can occur on various orifices of the body including internal body cavities and orifices, such as the uterus, rectum, urinary bladder, vulva, nasal cavity, peritoneal cavity, nasopharynx, oropharynx, oesophagus, trachea, bronchi and the vagina. ${ }^{5}$

Different chemicals for leech removal have been utilized and include anesthetics drugs like lidocaine and topical anesthetic spray. Salt, saline, vinegar, alcohol, and heat are also viable options. Of these, saltwater has been shown to be effective in causing the leech to relax and release.Vaginal bleeding resulting from leech bite is rare, but when it occurs, it may be of severe morbidity. ${ }^{2-4}$

In the present case report that happened at Kabaya district hospital, a six year old child with vaginal bleeding that turned out to be caused by vaginal leech infestation is presented.

Kabaya district hospital is a rural hospital with 144-bed capacity and serves 188,902 inhabitants and is geographically difficult to access due to the lack of reliable roads and bridges, especially in the rainy season.
\end{abstract}

\section{CASE REPORT}

Thepresent caseisasixyears old female child admitted 1 at Kabaya district hospital, Ngororero district in Northern Province of Rwanda on 19 December 2020 with complaints of pelvic pain and vaginal bleeding for 1 week. The child is $4^{\text {th }}$ child in fiveincluding threegirls and twoboys. She is born from a farming family.Her mother believed that the child was raped by a 10-year-old boy and she was admitted in hospital

On physical examination at admission, she was noted to be with normal anthropometric measures after plotting on the WHO curves weight: $19 \mathrm{~kg}$, Height: $107 \mathrm{~cm}$. The child was asthenic with the following vital signs: temperature of $36.8^{\circ} \mathrm{C}$, heart rate of 112 beats per minute, respiratory rate of 24 cycles per minute, and oxygen saturation of $97 \%$ on room air. Capillary refill time was below two seconds, and the extremities were warm. She had conjunctiva and palmo-plantar pallor. There was no lymphadenopathies, no hepatosplenomegaly, no petechiae, no bruises, and no laceration on vulva seen. The rest of the physical exam was unremarkable.

The child was treated with ampicillin IV 300mg three times a day for three days then discharged.
Two days after discharge from the hospital, she was readmittedwith profuse vaginal bleeding. Vitamin K5mg IM was prescribed but two days later 26 December 2020, the child was still bleeding and was re-examined during ward round.

Her temperature was $37.4^{\circ} \mathrm{C}$, Pulse $104 \mathrm{bpm}$, Saturation: $92 \%$ and she had pale conjunctiva. On vagina examination by a general practitioner, a foreign body was seen in the vagina attached on vagina wall and was removed using a forceps. After removal, the foreign body was found to be a live leech of about $5 \mathrm{~cm}$ in length (Figure 1).

Since then the bleeding subsided.A full blood count done after removing the leech revealed anemia with hemoglobin of $5.9 \mathrm{~g} / \mathrm{dl}$, hematocrit of 17.8 , platelets of $244 \times 10^{3}$ and the child received three Pediatric units of packed red blood cells. On control full blood count after transfusion, she had hemoglobin of $8.6 \mathrm{~g} / \mathrm{dl}$ and she was discharged on iron supplement. Furthermore on retrospective history taking before discharge from the hospital, the mother reported living near a stream of water that never dries up,that contains parasites similar to the one removed from her child's genitalia and that her child usually plays near the stream. 


\section{FIGURE 1. Leech Removed from the Vagina of a Six Years Old Child}

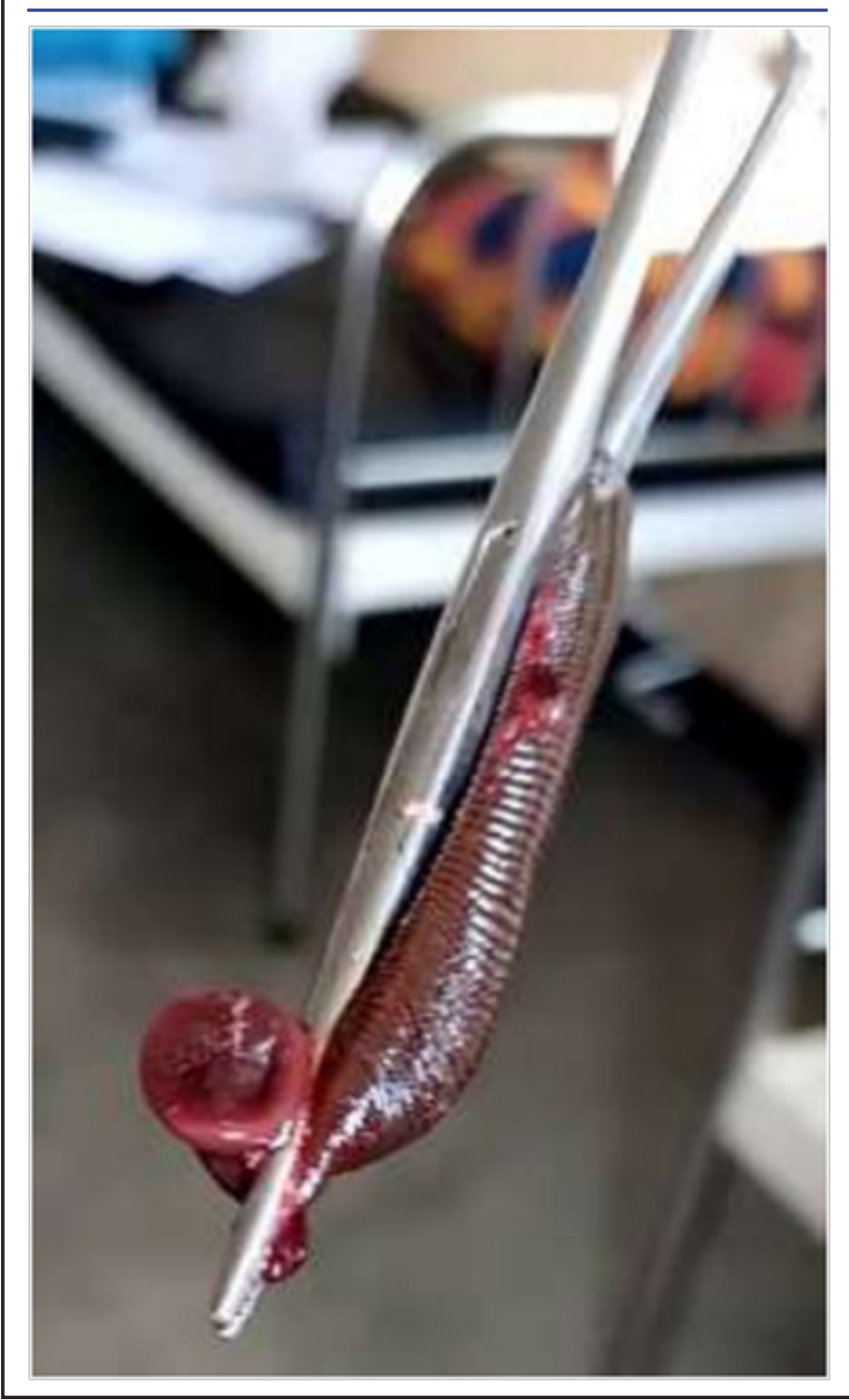

\section{DISCUSSION}

Globally, leech bites is a rare event and morbidities associated with leeches have been less discussed with most cases reported being from the tropics. ${ }^{6,7}$ Between January 1, 2004 and December 31, 17 cases of leech infestation through body orifices in children were managed. This is a retrospective study on age, sex, route of leech entry, investigation and treatment, and outcome. Results Age ranged from 4.5 to 11 years (mean $6.4 \pm 1.8$ Locally only one case report of leech bites in upper gastrointestinal tract has been reported so far, and no gynecological case of leech bite has been reported in Rwanda. ${ }^{8}$ Scarcity of data for abnormal vaginal bleeding resulting from leech bite is usually translated into being ignored among the potential differential diagnosis. This was the case in this child since the diagnosis of leech infestation was missed on the first admission, and found when the child was re- admitted in hospital. This case report illustrated the need to consider not only sexual abuse but also possibility of vaginal foreign body in particular leech bite.

\section{CONCLUSION}

As earlier discussed, this case report alertsclinicians to consider leech bite among differential diagnosis while dealing with patients with vaginal bleeding and living near a stream of water containingparasites. Foreign body should be excluded for any pediatric patient suspected to be a victim of rape.

\section{REFERENCES}

1. Tilahun T. Vaginal Leech Infestation: A Rare Cause of Hypovolumic Shock In Postmenopausal Woman. Ethiop J Health Sci. 2015;25(4):377-380. doi: $10.4314 /$ ejhs.v25i4. 13

2. Wiwanitkit $V$. ENT bleeding and leech bite. Adv Biomed Res. 2013;2:64. doi:10.4103/2277-9175.115818

3. Askari N, Eshaghian A. Otorrhagia bleeding due to leech bite. Adv Biomed Res. 2012;1:15. doi:10.4103/22779175.96041

4. Lok U, Bozkurt S, Okur M, Gulacti U, Hatipoglu S. A rare case of adverse effects caused by leech' bite. Am J Case Rep. 2013;14:191-193. doi:10.12659/AJCR.883936

5. Hasanzadeh $M$, Zarrinfar $H$, Najiari M. Unusual vaginal bleeding due to a leech bite in a girl from a tropical area: A case report. Rev Soc Bras Med Trop. 2019;52(March):0-2. doi: 10.1590/0037-8682-0425-2018

6. Hannan MJ, Hoque MM. Leech infestation in children through body orifices: Experience in a hospital in bangladesh. World J Surg. 2012;36(9):2090-2092. doi:10.1007/s00268-012$1633-x$

7. Lepage P, Serufilira A, Bossuyt M. Severe anaemia due to leech in the vagina. Ann Trop Paediatr. 1981;1(3): 189-190. doi: 10.1 080/02724936.1981.11748085

8. Rutagumba D, Niyoyita B, Nyirasafari R. Severe anemia by a leech infestation in a pediatric patient: A case report. Rwanda Med J. 2020;77(2): 1-3.

\section{Peer Reviewed}

Competing Interests: None declared.

Funding: This study was not funded

Received: 14 March 2021; Accepted: 01 November 2021

Cite this article as Sebazungu T, Kabungo KP, Manirakiza E, Dushimiyimana B. Leech Infestation in the Vulvar Region: Causes of Vaginal Bleeding in a Six Years Old Child. East Afr Health Res J. 2021;5(2):142-143. https://doi.org/10.24248/ eahrj.v5i2.664

(C) Sebazungu et al. This is an open-access article distributed under the terms of the Creative Commons Attribution License, which permits unrestricted use, distribution, and reproduction in any medium, provided the original author and source are properly cited. To view a copy of the license, visit http:// creativecommons.org/licenses/by/4.0/. When linking to this article, please use the following permanent link: https://doi. org/10.24248/eahrj.v5i2.664 